\section{Treating dental patients on new anticoagulant drugs}

Aust Prescr 2017;40:48

http://dx.doi.org/10.18773/austprescr.2017.022

I just have two questions on the use of anticoagulants on dental patients. ' First, in the paragraph on managing risk it says:

Before undertaking any treatment, dentists must obtain a thorough medical history from the patient. This includes the name, dose and prescriber of all drugs.

Does the author really mean that the prescriber should be noted for each drug? I am wondering whether this is an error and perhaps was meant to be duration, or purpose? If not, for what reason should the prescriber be noted? This would be difficult information for many patients to provide accurately and difficult to substantiate for long-term therapy.

Second, there is no mention of the use of postextraction tranexamic acid mouth rinse in this article. Despite strong support for its use after dental extractions in patients on warfarin, there are mixed opinions within the dental profession on the role of this mouthwash for patients on direct-acting oral anticoagulants.

Certainly, there is no evidence that it actually works and the absence of a proprietary product makes it difficult to support. However, many dental practitioners use it with the new oral anticoagulants just in case. A statement in the article on its role would have been helpful.

Geraldine Moses

Senior clinical and drug information pharmacist Mater Pharmacy Services

Adjunct associate professor

School of Pharmacy

University of Queensland

Brisbane

\section{REFERENCE}

1. Daly C. Treating patients on new anticoagulant drugs. Aust Prescr 2016;39:205-7. http://dx.doi.org/10.18773/ austprescr.2016.085

Christopher Daly, the author of the article, comments:

It should be standard practice for dentists to record the name of the patient's GP and any specialist physicians as they may need to be contacted to discuss the patient's medical status or medicines. It also provides a medicolegal record in the patient's notes. When listing the medicines, it is necessary to record the prescriber as it is not uncommon for patients to be prescribed drugs from both their GP and specialists. During a dental visit, it should be standard practice to review and update the patient's medical status as well as prescription and over-the-counter medicines.

For patients on warfarin, randomised controlled trials have shown that tranexamic acid mouthwash prevents bleeding after dental extractions. ${ }^{1-3}$ No such trials have been reported for the new anticoagulants. The dental management guideline for patients taking new anticoagulant drugs does not advise using tranexamic acid mouthwash as there is insufficient evidence to show any additional benefit over local measures (haemostatic plugs, suturing and compression). ${ }^{4}$

Whereas warfarin inhibits synthesis of coagulation factors II, VII, IX and X, the new anticoagulants directly inhibit one specific factor - either thrombin (dabigatran) or factor Xa (apixaban and rivaroxaban). Thus, the clotting cascade beyond factor $X$ is irreversibly turned off while these drugs are in the circulation. In the absence of evidencebased data of efficacy and on the basis of the pharmacological effects of the new anticoagulants, tranexamic acid mouthwash is not recommended as a post-extraction measure.

\section{Christopher Daly}

Chair (former)

Dental Therapeutics Committee

Australian Dental Association

\section{REFERENCES}

1. Sindet-Pedersen S, Ramström G, Bernvil S, Blombäck M. Hemostatic effect of tranexamic acid mouthwash in anticoagulant-treated patients undergoing oral surgery. N Engl J Med 1989:320:840-3. http://dx.doi.org/10.1056/ NEJM198903303201305

2. Borea G, Montebugnoli L, Capuzzi P, Magelli C. Tranexamic acid as a mouthwash in anticoagulanttreated patients undergoing oral surgery. An alternative method to discontinuing anticoagulant therapy. Oral Surg Oral Med Oral Pathol 1993;75:29-31. http://dx.doi.org/10.1016/0030-4220(93)90401-O

3. Ramström G, Sindet-Pedersen S, Hall G, Blombäck M, Alander U. Prevention of postsurgical bleeding in oral surgery using tranexamic acid without dose modification of oral anticoagulants. J Oral Maxillofac Surg 1993:51:1211-6. http://dx.doi.org/10.1016/S0278-2391(10)80291-5

4. Scottish Dental Clinical Effectiveness Programme. Management of dental patients taking anticoagulants or antiplatelet drugs. Dental clinical guidance. Dundee: SDCEP; 2015. www.sdcep.org.uk/ published-guidance/anticoagulants-and-antiplatelets [cited 2017 Mar 1] 